\title{
Nationwide Survey of Multidisciplinary Care and Cardiac Rehabilitation for Patients With Heart Failure in Japan - An Analysis of the AMED-CHF Study -
}

\author{
Kentaro Kamiya, PhD; Takanobu Yamamoto, MD, PhD; Miyuki Tsuchihashi-Makaya, PhD; \\ Toshimi Ikegame; Tetsuya Takahashi, PhD; Yukihito Sato, MD, PhD; \\ Norihiko Kotooka, MD, PhD; Yoshihiko Saito, MD, PhD; \\ Hiroyuki Tsutsui, MD, PhD; Hiroaki Miyata, PhD; Mitsuaki Isobe, MD, PhD
}

\begin{abstract}
Background: The purpose of this study was to clarify the implementation rate of multidisciplinary heart failure (HF) care and cardiac rehabilitation $(\mathrm{CR})$ in Japan, as well as the relationship between implementation rates and characteristics of the facility.
\end{abstract}

\begin{abstract}
Methods and Results: Survey participants were cardiologists who are members of the Japan Heart Failure Society and belonged to 1 of 845 medical institutions that are members of the Japan Heart Failure Society, as of April 2016. A total of 288 institutions (34.1\%) returned the questionnaire. The percentages of hospitals implementing multidisciplinary HF care were $78.5 \%$ for inpatients and $32.6 \%$ for outpatients with HF. Inpatient and outpatient CR for HF had implementation rates of $80.4 \%$ and $56.5 \%$, respectively. In addition, very few HF patients $(7.3 \%, 3,741 / 51,323$ patients) received outpatient $\mathrm{CR}$. Both the presence of nurses certified in chronic HF care and registered CR instructors on staff were consistently associated with implementation of multidisciplinary HF care, and Japanese Circulation Society training hospitals, lower number of hospital beds, and presence of registered CR instructors on staff were consistently associated with implementation of CR.
\end{abstract}

Conclusions: This first nationwide survey demonstrated that the implementation rates of multidisciplinary care and CR for HF, especially for outpatients, are low in Japan. Skilled healthcare professionals are expected to play important roles in the widespread implementation of this type of HF care in Japan.

Key Words: Cardiac rehabilitation; Heart failure; Multidisciplinary care

A rapid increase in the number of patients with chronic heart failure (HF) is expected with aging of the population in Japan. According to the Japanese Registry of All cardiac and Vascular Diseases (JROAD) survey carried out by the Japanese Circulation Society (JCS), the number of patients hospitalized for HF in 2017 was 260,000 , increasing by 10,000 people every year since the survey started in 2013. ${ }^{1}$ Once HF becomes severe; the prognosis is extremely poor, activities of daily life are restricted by symptoms, including shortness of breath with exertion, and quality of life (QOL) is markedly decreased. Acute decompensated HF (ADHF) usually leads to hospital admission for intensive care, resulting in enormous medical costs. The hospital readmission rate for patients with $\mathrm{HF}$ is high, and observational studies that have followed patients with acute HF in Japan for 9 years have revealed that, although length of hospital stay has decreased remarkably, the hospital readmission rates within 30 days and 1 year after discharge have not been improved, remaining the same over time. ${ }^{2}$

To prevent hospital readmission because of exacerbation of HF, which is an important goal in HF treatment, strengthening treatment and management after discharge from hospital are essential. For instance, it is important to

Received March 20, 2019; revised manuscript received April 25, 2019; accepted May 4, 2019; J-STAGE Advance Publication released online June 11, 2019 Time for primary review: 27 days

Department of Rehabilitation, School of Allied Health Sciences (K.K.), School of Nursing (M.T.-M.), Kitasato University, Sagamihara; Department of Cardiovascular Medicine, Tokyo Medical and Dental University, Tokyo (T.Y.); Department of Nursing, Sakakibara Heart Institute, Fuchu (T.I.); Department of Physical Therapy, Juntendo University, Tokyo (T.T.); Department of Cardiology, Hyogo Prefectural Amagasaki General Medical Center, Amagasaki (Y. Sato); Department of Cardiovascular Medicine, Saga University, Saga (N.K.); Department of Cardiovascular Medicine, Nara Medical University, Kashihara (Y. Saito); Department of Cardiovascular Medicine, Kyushu University Graduate School of Medical Sciences, Fukuoka (H.T.); Department of Health Policy and Management, School of Medicine, Keio University, Tokyo (H.M.); and Sakakibara Heart Institute, Fuchu (M.I.) Japan

Mailing address: Mitsuaki Isobe, MD, PhD, Sakakibara Heart Institute, 3-16-1 Asahi-cho, Fuchu 183-0003, Japan. E-mail: misobe@shi.heart.or.jp

ISSN-1346-9843 All rights are reserved to the Japanese Circulation Society. For permissions, please e-mail: cj@j-circ.or.jp 
implement a disease management program that consists of multidisciplinary interventions, including provision of precise knowledge about HF and its treatment for members of the patient's family, improvement in lifestyle habits of the patient, support for self-care behaviors, exercise therapy, psychological support and readjustment of the living environment. ${ }^{3}$ Cardiac rehabilitation (CR), in particular, is a disease management program for patients with heart disease; in Europe and the USA, it has been reported that outpatient CR administered by multidisciplinary professionals for patients at high risk of hospital readmission plays a role in the disease management program, leading to improved exercise tolerance and QOL and reduction of hospital readmission rates. ${ }^{4}$ Disease management through CR has already begun in Japan, but neither CR for patients with $\mathrm{HF}$, especially after discharge from the hospital, nor the actual circumstances of such interventions by multidisciplinary healthcare professionals are clear. It is essential to clarify the reality of inpatient and outpatient CR and collaboration among multidisciplinary healthcare professionals in order to establish clinical guidelines for providing appropriate medical care for patients with $\mathrm{HF}$ with the aims of improving QOL and avoiding hospital readmission.

The purpose of this study was to clarify the implementation rate of inpatient and outpatient CR by intervention of multidisciplinary professionals for patients with $\mathrm{HF}$ in cardiovascular clinics in Japan, as well as the relationship between implementation rates and characteristics of the facility.

\section{Methods}

\section{Study Participants}

This investigation was a cross-sectional observation survey, and the survey participants were cardiologists who were members of the Japan Heart Failure Society, belonging to 1 of 845 medical institutions that are members of the Japan Heart Failure Society, as of April 2016. This study was conducted with approval from the Tokyo Medical and Dental University Ethics Review Committee. A written explanation about the investigation and a consent form were mailed together with the questionnaire to the participants. Participants were requested to sign the consent form if they agreed to participate in the study and send it back together with the completed questionnaire form to the research secretariat installed within the Department of Cardiovascular Medicine at Tokyo Medical and Dental University. Survey participants were asked to return their questionnaires to the office of the secretariat within 1 month of receipt. No reminders were sent to non-responders. The number of facilities that had patients returning the questionnaire was 288 , and the response rate was $34.1 \%$, of which 270 responses were valid.

\section{Data Collection}

The survey was a self-administered questionnaire, consisting of information about the hospital and the implementation of inpatient or outpatient multidisciplinary HF care (excluding CR), and of inpatient and outpatient CR for patients with HF.

As for hospital characteristics, the survey investigated whether the facility was a diagnosis procedure combination (DPC) hospital, a JCS training hospital or affiliated hospital, fulfilled the facility standard of cardiac and vascular disease rehabilitation unit (I) or (II), the number of

\begin{tabular}{|c|c|}
\hline $\mathrm{n}$ & 270 \\
\hline DPC hospital, n (\%) & $241(89.3)$ \\
\hline JCS training hospital, n (\%) & $226(83.7)$ \\
\hline JCS associated hospital, $\mathrm{n}(\%)$ & $62(23.0)$ \\
\hline No. of HF hospitalizations (per year) & $190.1 \pm 159.6$ \\
\hline \multicolumn{2}{|l|}{ Hospital size } \\
\hline No. of hospital beds & $502.2 \pm 283.5$ \\
\hline$\geq 500$ & $38(14.1)$ \\
\hline 200-499 & $109(40.4)$ \\
\hline$<200$ & $123(45.6)$ \\
\hline Cardiology beds, n (\%) & $245(90.7)$ \\
\hline No. of cardiology beds & $41.9 \pm 27.9$ \\
\hline CCU beds, $\mathrm{n}(\%)$ & $147(54.4)$ \\
\hline No. of $\mathrm{CCU}$ beds & $4.3 \pm 5.0$ \\
\hline \multicolumn{2}{|l|}{ Hospital staffing } \\
\hline Cardiologist (full-time), n (\%) & $258(95.6)$ \\
\hline No. of cardiologists & $11.8 \pm 10.8$ \\
\hline JCS certified board member, $\mathrm{n}(\%)$ & $254(94.1)$ \\
\hline No. of board-certified members of JCS & $7.6 \pm 6.6$ \\
\hline Registered instructor of CR, $\mathrm{n}(\%)$ & $209(77.4)$ \\
\hline No. of registered instructors of $\mathrm{CR}$ & $3.6 \pm 3.7$ \\
\hline Advanced instructor of CR, $n(\%)$ & $59(21.9)$ \\
\hline No. of advanced instructors of CR & $0.3 \pm 0.7$ \\
\hline Nurses certified in chronic HF nursing, $\mathrm{n}(\%)$ & $113(41.9)$ \\
\hline No. of nurses certified in chronic HF nursing & $0.5 \pm 0.6$ \\
\hline
\end{tabular}

CCU, cardiac care unit; CR, cardiac rehabilitation; DPC, Diagnosis Procedure Combination; HF, heart failure; JCS, Japanese Circulation Society.

hospital beds and cardiology beds, and the number of inpatients with HF from January 1st to December 31st 2015 (real number) and full-time cardiologists, availability of cardiac care unit (CCU), the number of CCU beds, cardiovascular specialists, CR instructors, registered and advanced $\mathrm{CR}$ instructors and nurses certified in chronic HF care.

Questions about inpatient or outpatient interventions of multidisciplinary HF care, the implementation and the methods (case conference, individual HF education, group HF education), and the types of professionals who participated in multidisciplinary HF care were asked. Regarding the implementation status of inpatient and outpatient CR for patients with HF, whether or not CR had been implemented and the number of cases reported from January 1 , 2015 to December 31, 2015 were examined.

\section{Statistical Analysis}

For the actual hospital characteristics, multidisciplinary HF care and $\mathrm{CR}$, means and standard deviations were calculated for continuous variables, and proportions were calculated for categorical variables. The associations between hospital characteristics, implementation of multidisciplinary $\mathrm{HF}$ care and CR were analyzed using a chi-square test and a multivariate logistic regression analysis. In the multivariate model, if the facility was a DPC hospital/JCS training hospital, the number of hospital beds, availability of CCU, number of cardiologists, presence of registered instructors of $\mathrm{CR}$, advanced instructors of CR and nurse certified in chronic HF care were used as independent variables.

A two-tailed P-value $<0.05$ was taken to indicate statisti- 


\section{A) Inpatient Multidisciplinary HF Care}

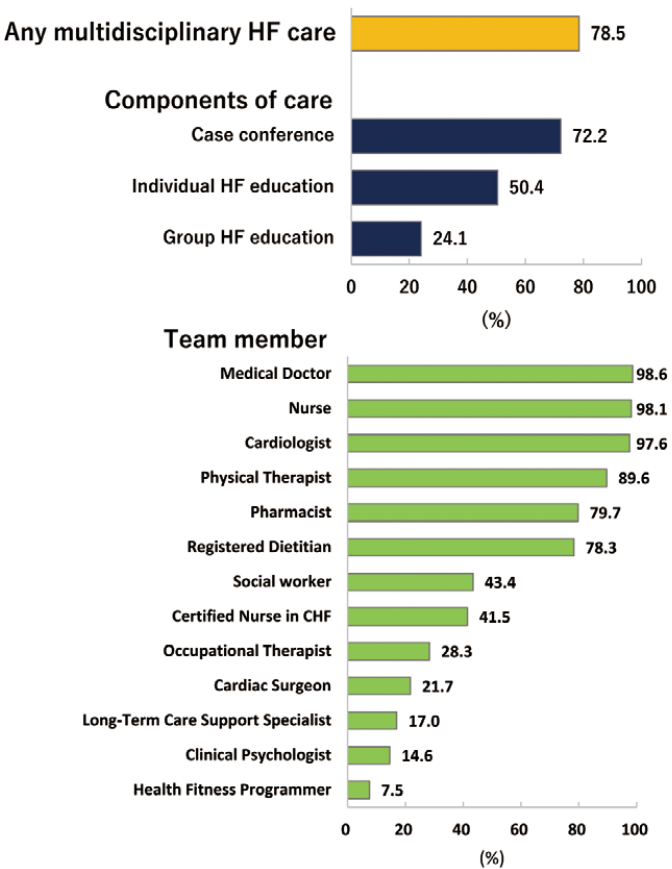

\section{B) Outpatient Multidisciplinary HF Care}

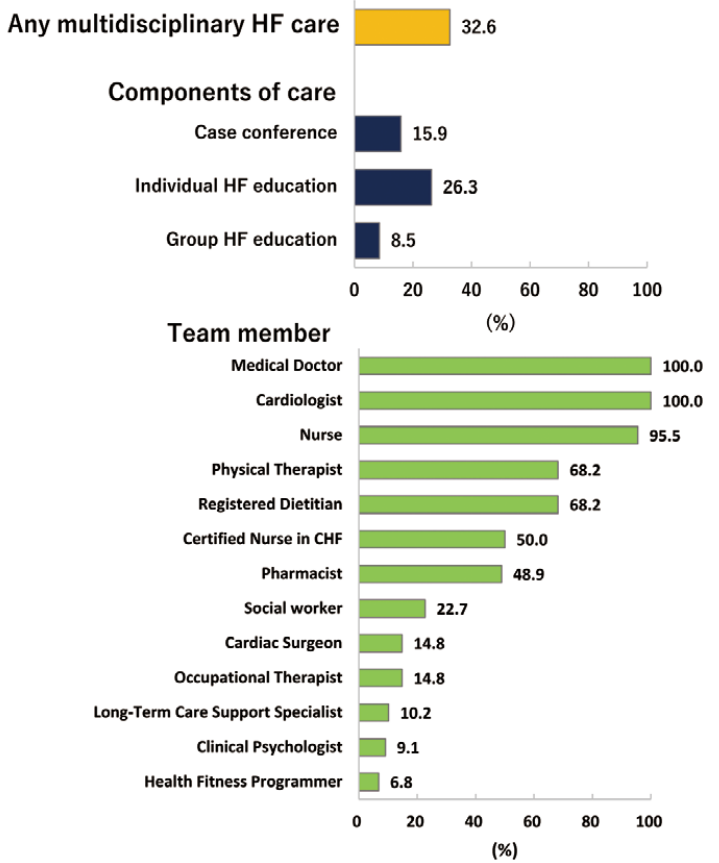

Figure 1. (A,B) Implementation rates and team members of multidisciplinary heart failure (HF) care. CHF, chronic heart failure. Medical doctor includes both cardiologists and non-cardiologists.

A) Inpatient Cardiac Rehabilitation

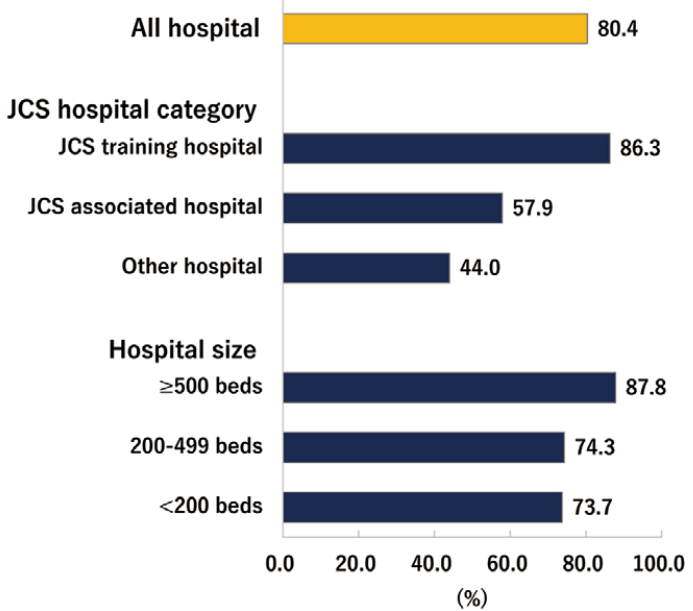

\section{B) Outpatient Cardiac Rehabilitation}

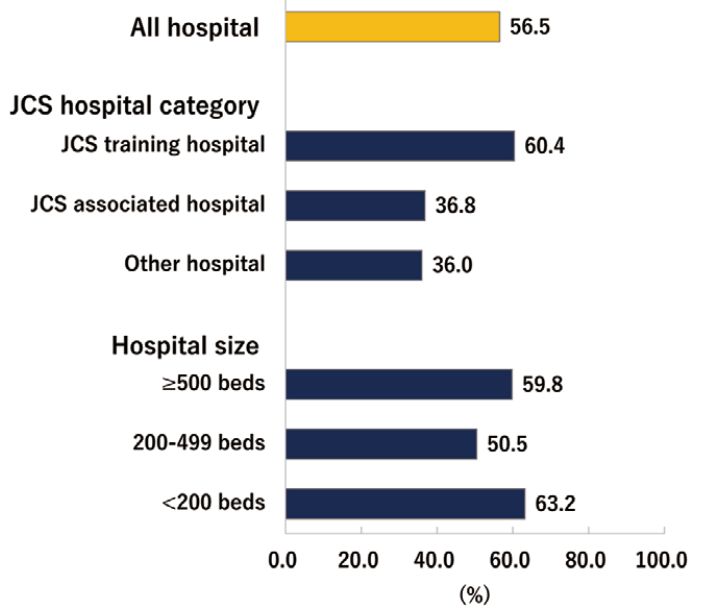

Figure 2. (A,B) Implementation rates of cardiac rehabilitation per hospital for patients with heart failure. JCS, Japanese Circulation Society.

cal significance. Analyses were performed using SPSS 22.0 (IBM Corporation, New York, NY, USA).

\section{Results}

Table 1 is a summary of the hospital data. Effective responses were obtained from 270 hospitals, including 241 DPC hospitals and 226 JCS training hospitals. The mean number of 


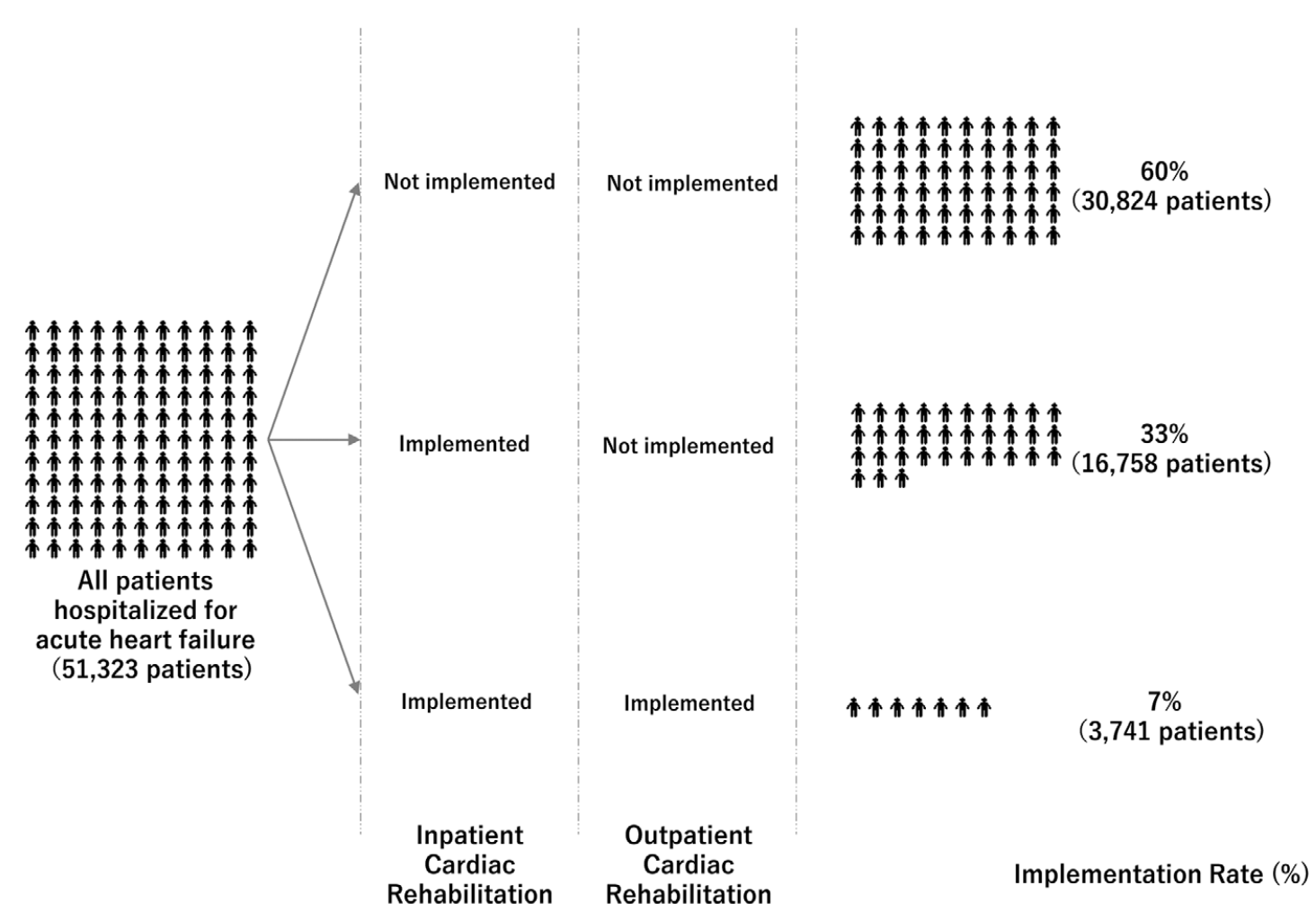

Figure 3. Percentages of heart failure patients referred for inpatient and/or outpatient cardiac rehabilitation.

\begin{tabular}{|c|c|c|c|c|c|c|c|c|c|c|c|c|}
\hline & \multicolumn{3}{|c|}{$\begin{array}{c}\text { Inpatient } \\
\text { multidisciplinary HF care }\end{array}$} & \multicolumn{3}{|c|}{$\begin{array}{c}\text { Outpatient } \\
\text { multidisciplinary HF care }\end{array}$} & \multicolumn{3}{|c|}{ Inpatient CR } & \multicolumn{3}{|c|}{ Outpatient CR } \\
\hline & OR & $95 \% \mathrm{Cl}$ & $P$ value & OR & $95 \% \mathrm{Cl}$ & $P$ value & OR & $95 \% \mathrm{Cl}$ & $P$ value & OR & $95 \% \mathrm{Cl}$ & $P$ value \\
\hline DPC hospital & 1.19 & $0.35-4.10$ & 0.781 & 0.78 & $0.27-2.30$ & 0.654 & 0.96 & $0.20-4.65$ & 0.961 & 0.67 & $0.19-2.29$ & 0.519 \\
\hline $\begin{array}{l}\text { JCS training } \\
\text { hospital }\end{array}$ & 1.12 & $0.40-3.14$ & 0.833 & 0.61 & $0.24-1.53$ & 0.292 & 4.65 & $1.30-16.59$ & 0.018 & 2.99 & $1.13-7.91$ & 0.028 \\
\hline $\begin{array}{l}\text { No. of hospital } \\
\text { beds } \\
\text { (per } 100 \text { beds) }\end{array}$ & 0.85 & $0.70-1.03$ & 0.096 & 0.91 & $0.78-1.06$ & 0.221 & 0.70 & $0.52-0.94$ & 0.019 & 0.83 & $0.70-0.97$ & 0.018 \\
\hline CCU bed & 1.18 & $0.59-2.34$ & 0.643 & 0.91 & $0.51-1.62$ & 0.741 & 2.88 & $1.07-7.76$ & 0.037 & 1.16 & $0.65-2.08$ & 0.617 \\
\hline No. of cardiologists & 1.02 & $0.97-1.08$ & 0.483 & 1.04 & $1.00-1.07$ & 0.053 & 1.15 & $1.03-1.30$ & 0.016 & 1.02 & $0.98-1.05$ & 0.443 \\
\hline $\begin{array}{l}\text { Registered } \\
\text { instructor of } \mathrm{CR}\end{array}$ & 5.14 & $2.35-11.26$ & $<0.001$ & 3.54 & $1.29-9.69$ & 0.014 & 27.68 & $9.82-78.02$ & $<0.001$ & 12.91 & $4.92-33.91$ & $<0.001$ \\
\hline $\begin{array}{l}\text { Advanced } \\
\text { instructor of } \mathrm{CR}\end{array}$ & 3.88 & $1.08-13.97$ & 0.038 & 0.96 & $0.48-1.92$ & 0.898 & 1.26 & $0.31-5.16$ & 0.744 & 1.94 & $0.92-4.10$ & 0.082 \\
\hline $\begin{array}{l}\text { Nurse certified in } \\
\text { chronic HF }\end{array}$ & 3.47 & $1.55-7.76$ & 0.002 & 3.11 & $1.70-5.67$ & $<0.001$ & 2.41 & $0.82-7.09$ & 0.109 & 1.62 & $0.87-3.01$ & 0.125 \\
\hline
\end{tabular}

Abbreviations as in Table 1.

total hospital beds and of cardiology beds were $502 \pm 284$ and $42 \pm 28$, respectively. Almost all hospitals had cardiologists and board-certified JCS cardiologists on staff $(95.6 \%$ and $94.1 \%$, respectively). On the other hand, only $77 \%$ and $42 \%$ of hospitals had registered instructors of CR and chronic HF certified nurses, respectively.

\section{Status of Multidisciplinary HF Care}

The implementation rate of multidisciplinary HF care and the team members involved are summarized in Figure 1. The rates of implementation of multidisciplinary HF care were $78.5 \%$ for inpatients with $\mathrm{HF}$ and $32.6 \%$ for outpatients with HF. With regard to the components of the multidisciplinary HF care, case conference, individual HF education, and group HF education were implemented in 
$72.2 \%, 50.4 \%$, and $24.1 \%$ of hospitals for inpatient $\mathrm{HF}$, and in $15.9 \%, 26.3 \%$, and $8.5 \%$ hospitals for outpatient $\mathrm{HF}$, respectively.

\section{Implementation of CR}

The implementation rates of inpatient and outpatient CR were $80.4 \%$ and $56.5 \%$, respectively. The CR implementation rate was significantly higher in JCS training hospitals than in the other types of facilities $(\mathrm{P}<0.01$ for inpatient $\mathrm{CR}$ and $\mathrm{P}=0.01$ for outpatient $\mathrm{CR}$, Figure 2).

\section{Rate of Participation in CR}

Of 51,323 patients hospitalized for HF in the hospitals included in the survey, $60 \%$ did not receive inpatient and outpatient CR, 33\% of patients received only inpatient $\mathrm{CR}$, and only $7 \%$ of patients received inpatient and outpatient CR (Figure 3).

\section{Logistic Regression Analysis for Associations of Hospital Characteristics With Implementation of Multidisciplinary HF Care and CR}

The presence of registered CR instructors, advanced CR instructors, and nurses certified in chronic HF care on staff showed significant associations with implementation of inpatient multidisciplinary HF care (Table 2). The presence of registered CR instructors and nurses certified in chronic HF care on staff showed significant associations with implementation of outpatient multidisciplinary HF care $(\mathrm{P}<0.05)$. JCS training hospital, lower number of hospital beds, availability of CCU beds, number of cardiologists, and presence of registered CR instructors on staff were significantly associated with implementation of inpatient CR $(\mathrm{P}<0.05)$. JCS training hospital, lower number of hospital beds, and presence of registered CR instructors on staff showed significant associations with implementation of outpatient $\mathrm{CR}(\mathrm{P}<0.05)$.

\section{Discussion}

\section{Primary Findings}

This is the first multicenter survey to examine the implementation rate of multidisciplinary care and CR for patients with HF in Japan. The primary findings of this study were as follows: (1) inpatient and outpatient multidisciplinary HF care had implementation rates of $78.5 \%$ and $32.6 \%$, respectively; (2) inpatient and outpatient CR for HF had implementation rates of $80.4 \%$ and $56.5 \%$, respectively; (3) very few HF patients $(7.3 \%, 3,741 / 51,323$ patients) received outpatient CR; (4) JCS training hospital, lower number of hospital beds, and presence of registered CR instructors on staff were consistently associated with implementation of inpatient and outpatient CR; and (5) presence of nurses certified in chronic HF care and registered CR instructors on staff were consistently associated with implementation of inpatient and outpatient multidisciplinary HF care.

\section{Implementation Rate and Members of Multidisciplinary HF Care Team}

The most effective approach to complex HF care appears to be multidisciplinary care. ${ }^{\mathbf{5 6}}$ The team-based multidisciplinary approach has been shown to be superior to standard care in HF patients with regard to reducing the risks of death and rehospitalization, length of hospital stay, and QOL.6-9 Patients receiving multidisciplinary HF care have been reported to show higher proportions of treatment with angio- tensin-converting enzyme inhibitors and $\beta$-blockers, earlier recognition of the signs and symptoms of $\mathrm{HF}$, increased rates of counseling regarding smoking cessation, shorter length of hospital stay, and reduced medical costs. ${ }^{10}$ Therefore, the most recent HF guidelines recommend team-based multidisciplinary HF care. However, the implementation rate of team-based multidisciplinary HF care has not been widely surveyed in Japan.

The present study was performed to investigate the implementation rates and members of inpatient and outpatient multidisciplinary HF care teams and associated factors in Japan. The results indicated that the implementation rate of multidisciplinary HF care was low (inpatient, $78.5 \%$; outpatient, $32.6 \%$ ), and this HF care were provided by a variety of staff, including cardiologists, nurses, physical therapists, pharmacists, registered dieticians etc. The results of multivariable logistic regression analyses showed that the presence of nurses certified in chronic HF care and registered CR instructors on the hospital staff were consistently associated with implementation of inpatient and outpatient multidisciplinary HF care.

The Japanese Association of Cardiac Rehabilitation established a certification program for registered instructors of CR in 2000 and the Japanese Nursing Association launched a certification in chronic HF nursing in 2012. These skilled healthcare professionals are expected to play important roles in the widespread implementation of multidisciplinary HF care in Japan. ${ }^{11}$

\section{Implementation Rate of CR}

The availability of CR care is very low despite increasing trends in cardiovascular disease burden and deaths around the world, with only $38.8 \%$ of countries having active CR programs and some middle-income countries having as little as $1 \mathrm{CR}$ program per 6 million inhabitants. ${ }^{12}$ In Japan, Goto et $\mathrm{al}^{13}$ and Arakawa et $\mathrm{a} \mathbf{1}^{14}$ performed nationwide surveys of the implementation rate of CR for acute myocardial infarction (AMI) in responding cardiology training hospitals authorized by the JCS. They reported that the implementation rate of percutaneous coronary intervention was high (94\% in 2004 and $96 \%$ in 2009), but those of inpatient and outpatient CR were very low (inpatient, $55 \%$ in 2004 and $64 \%$ in 2009; outpatient, $9 \%$ in 2004 and $21 \%$ in 2009). Although the facilities investigated and sample size were different, the present study's results indicated that the implementation rate of CR in JCS training hospitals increased to $86.3 \%$ for inpatients and $60.4 \%$ for outpatients. Koyama reported that the number of medical institutions registered for CR in Japan had increased from 186 in 2005, to 495 in 2010, and 788 in 2013. ${ }^{15}$ In February 2019, we performed a survey of the number of institutions registered for CR using the same method as in that study, and found that the number of $\mathrm{CR}$ facilities had continued to increase steadily to 1,337 . Although desirable, this increase in registered CR facilities remains less than optimal, with further increases in outpatient CR facilities needed because the decreasing length of hospital stay prevents patients from receiving sufficient $\mathrm{CR}$ care during hospitalization.

The implementation of CR is influenced by a number of factors, including hospital size, procedure volumes, and geographic location, as well as the number of medical staff and staff expertise. In the present study, JCS training hospital, lower number of hospital beds, and presence of registered CR instructors on staff were consistently associated with implementation of inpatient and outpatient CR. 
These observations suggest that the implementation of CR programs is influenced by these hospital characteristics and presence of skilled healthcare professionals.

\section{Patient Participation Rate in CR}

Despite a hospital outpatient CR implementation rate of $56.5 \%$, inpatient and outpatient CR were implemented for only $7 \%$ of the patients included in the present study. Goto et al reported a similar rate in patients suffering from AMI. ${ }^{13}$ This gap could be explained at 3 inter-related levels: patient, provider, and system levels. ${ }^{12}$ Patient factors related to this gap in the CR implementation rate include older age, low socioeconomic status, time conflicts, patient disinterest, and comorbidities. ${ }^{16}$ At the provider level, low levels of physician endorsement of $\mathrm{CR}$ and lack of resources to deliver outpatient $\mathrm{CR}$ are frequently described as being related to a low rate of CR implementation.12,17 At the level of the healthcare system, the low CR implementation rate has been reported to be related to financial constraints, distance, and transportation problems. ${ }^{12,18}$

There have been few reports regarding the participation rate in outpatient CR among patients with HF globally. According to the Get With The Guidelines-Heart Failure registry involving $>100,000$ patients admitted with $\mathrm{HF}$ at 338 institutions in the USA, the rates of participation in outpatient $\mathrm{CR}$ were reported to be extremely low, with rates of $2.3 \%$ among veterans and $2.6 \%$ among beneficiaries of Medicare hospitalized for HF in the USA. These observations suggest the vast underutilization of outpatient $\mathrm{CR}$ among patients with HF. ${ }^{18}$

To improve this situation, the American College of Cardiology/American Heart Association recently revised the CR performance and quality measure set with 6 new performance measures and 3 new quality measures, including exercise training referral and enrollment for HF with reduced ejection fraction, and CR enrollment and adherence. ${ }^{19}$ This new measurement set is expected to improve both the CR participation rate and outcomes.

\section{Study Limitations}

First, this was a retrospective questionnaire-based survey of institutions. Therefore, we could not confirm the accuracy of data on an individual patient basis. Second, the survey participants were only cardiologists who are members of the Japan Heart Failure Society and the response rate was relatively low in the present survey $(34.1 \%)$. This could have led to a potential bias suggesting that a majority of answers were provided by medical doctors interested in $\mathrm{HF}$ care. If this was the case, the implementation rate of multidisciplinary HF care and CR may have been overestimated. Finally, this survey allowed us to analyze possible barriers to the implementation of CR. However, we did not collect detailed demographic and/or clinical information regarding the patient populations.

\section{Conclusions}

This multicenter survey of multidisciplinary care and CR for HF showed that the rates of implementation of both multidisciplinary care and CR are low in Japan. Considering our aging society and associated future increases in the number of patients with $\mathrm{HF}^{20}$ it will be necessary to increase the implementation rates of multidisciplinary care and CR for HF patients. Skilled healthcare professionals, including nurses certified in chronic HF and registered CR instructors, are expected to play important roles in the widespread implementation of multidisciplinary HF care and CR in Japan.

\section{Acknowledgments}

The authors would like to acknowledge the directors and staff of the 845 medical institutions that are members of the Japan Heart Failure Society for their cooperation with this survey.

\section{Disclosures}

This study was supported by Research Grants from the Japan Agency for Medical Research and Development (AMED) (16ek0210058 h0001).

\section{References}

1. The Japanese Registry of All cardiac and vascular Diseases (JROAD): Annual Report 2017. http://www.j-circ.or.jp/jittai_chosa/ jittai chosa2016web.pdf (accessed March 1, 2019).

2. Shiraishi Y, Kohsaka S, Sato N, Takano T, Kitai T, Yoshikawa $\mathrm{T}$, et al. 9-year trend in the management of acute heart failure in Japan: A report From the National Consortium of Acute Heart Failure Registries. J Am Heart Assoc 2018; 7: e008687.

3. Isobe M. The heart failure "pandemic" in Japan: Reconstruction of health care system in the highly aged society. JMA J, doi:10.31662/jmaj.2018-0049.

4. Davidson PM, Cockburn J, Newton PJ, Webster JK, Betihavas $\mathrm{V}$, Howes L, et al. Can a heart failure-specific cardiac rehabilitation program decrease hospitalizations and improve outcomes in high-risk patients? Eur J Cardiovasc Prev Rehabil 2010; 17: 393 402.

5. Cooper LB, Hernandez AF. Assessing the quality and comparative effectiveness of team-based care for heart failure: Who, what, where, when, and how. Heart Fail Clin 2015; 11: 499-506.

6. Yancy CW, Januzzi JL Jr, Allen LA, Butler J, Davis LL, Fonarow GC, et al. 2017 ACC Expert Consensus Decision Pathway for Optimization of Heart Failure Treatment: Answers to 10 pivotal issues about heart failure with reduced ejection fraction. A report of the American College of Cardiology Task Force on Expert Consensus Decision Pathways. J Am Coll Cardiol 2018; 71: 201 230.

7. Rich MW, Beckham V, Wittenberg C, Leven CL, Freedland KE, Carney RM. A multidisciplinary intervention to prevent the readmission of elderly patients with congestive heart failure. $N$ Engl J Med 1995; 333: 1190-1195.

8. Phillips CO, Wright SM, Kern DE, Singa RM, Shepperd S, Rubin HR. Comprehensive discharge planning with postdischarge support for older patients with congestive heart failure: A meta-analysis. JAMA 2004; 291: 1358-1367.

9. Tsuchihashi-Makaya M, Matsuo H, Kakinoki S, Takechi S, Kinugawa S, Tsutsui H. Home-based disease management program to improve psychological status in patients with heart failure in Japan. Circ J 2013; 77: 926-933.

10. Rich MW, Gray DB, Beckham V, Wittenberg C, Luther P. Effect of a multidisciplinary intervention on medication compliance in elderly patients with congestive heart failure. Am J Med 1996; 101: $270-276$

11. Kuragaichi T, Kurozumi Y, Ohishi S, Sugano Y, Sakashita A, Kotooka N, et al. Nationwide survey of palliative care for patients with heart failure in Japan. Circ J 2018; 82: 1336-1343.

12. Turk-Adawi K, Sarrafzadegan N, Grace SL. Global availability of cardiac rehabilitation. Nat Rev Cardiol 2014; 11: 586-596.

13. Goto Y, Saito M, Iwasaka T, Daida H, Kohzuki M, Ueshima K, et al. Poor implementation of cardiac rehabilitation despite broad dissemination of coronary interventions for acute myocardial infarction in Japan: A nationwide survey. Circ J 2007; 71: $173-179$.

14. Arakawa T, Kumasaka L, Nakanishi M, Nagayama M, Adachi $\mathrm{H}$, Ikeda $\mathrm{K}$, et al. Regional clinical alliance path and cardiac rehabilitation after hospital discharge for acute myocardial infarction patients in Japan: A nationwide survey. Circ J 2016; 80: 1750 1755.

15. Koyama T. Trends in registered hospital and clinic on medical fee for cardiovascular rehabilitation: Current status of cardiac rehabilitation after 2012 revision of medical fee. Jpn J Card Rehabil 2014; 19: 250-255 (in Japanese).

16. Neubeck L, Freedman SB, Clark AM, Briffa T, Bauman A, Redfern J. Participating in cardiac rehabilitation: A systematic review and meta-synthesis of qualitative data. Eur J Prev Cardiol 
2012; 19: 494-503.

17. Balady GJ, Ades PA, Bittner VA, Franklin BA, Gordon NF, Thomas RJ, et al. Referral, enrollment, and delivery of cardiac rehabilitation/secondary prevention programs at clinical centers and beyond: A presidential advisory from the American Heart Association. Circulation 2011; 124: 2951-2960.

18. Park LG, Schopfer DW, Zhang N, Shen H, Whooley MA. Participation in cardiac rehabilitation among patients with heart failure. J Card Fail 2017; 23: 427-431.

19. Thomas RJ, Balady G, Banka G, Beckie TM, Chiu J, Gokak S, et al. 2018 ACC/AHA clinical performance and quality measures for cardiac rehabilitation: A report of the American College of Cardiology/American Heart Association Task Force on Performance Measures. J Am Coll Cardiol 2018; 71: 1814-1837.

20. Nagai T, Yoshikawa T, Saito Y, Takeishi Y, Yamamoto K, Ogawa $\mathrm{H}$, et al. Clinical characteristics, management, and outcomes of japanese patients hospitalized for heart failure with preserved ejection fraction: A report from the Japanese Heart Failure Syndrome With Preserved Ejection Fraction (JASPER) Registry. Circ J 2018; 82: 1534-1545. 